\title{
Mutagenic and carcinogenic actions of chromium and its compounds
}

\author{
Arstan Abdramanovich Mamyrbaev ${ }^{1}$ Timur Agataevich Dzharkenov ${ }^{1} \cdot$ \\ Zina Amangalievna Imangazina ${ }^{1} \cdot$ Umit Abulkhairovna Satybaldieva $^{1}$
}

Received: 6 March 2015/Accepted: 24 March 2015/Published online: 16 April 2015

(C) The Japanese Society for Hygiene 2015

\begin{abstract}
Numerous experimental observations have been made on microorganisms and culture of the cells of mammals as well as the accounting of the chromosomal aberrations in the bone marrow cells of the mammals and of human cells displayed that the chromium and its compounds possess a pronounced mutagenic effect. Translocation test, induction record of DNA damage and repair systems in the mammalian and human cells with greater precision proves the presence of the mutagenic effect of the chromium and its compounds, which in turn is dependent on dose and time of this metal intoxication. Chromium and its compounds have pronounced mutagenic effect, on increased admission to organism of mammals and protozoa.
\end{abstract}

Arstan Abdramanovich Mamyrbaev

asemaika@mail.ru

Timur Agataevich Dzharkenov

asemaika@mail.ru

Zina Amangalievna Imangazina

imanga_zina@mail.ru

Umit Abulkhairovna Satybaldieva

satybaldieva.u@mail.ru

1 West-Kazakhstan State Medical University Named After Marat Ospanov, Maresyev street 68, 030019 Aktobe City, The Republic of Kazakhstan
Keywords Chromium · Mutation · Genotoxicity · Marrow - Mammalian and human cells . The test system · Chromosomal aberrations

\section{Introduction}

Accounting methods of mutations in the somatic and germ cells of many representatives of the living world has been developed and standardized in the 60-70 years of the last century and the genetic activity of chemical substances of different classes and assignment was determined. The identification of mutagens, estimation of their risks to man and the principles of control of mutagens in the environment have been considered by the International Commission to the Protection from the mutagenic and carcinogenic compounds. The reports of the Commission defined the goals of the newly emerged mutations in morbidity of the population and strategy study of the mutagenic activity of the chemical compounds, approaches to control and limitation of the human with mutagens were considered.

WHO experts recommended the foundation of a strategy of screening of mutagens among newly synthesized chemicals, considered the basic methods and test systems of the evaluation of the genotoxicity in vivo and in vitro, as well as approaches to the interpretation of test results [1]. At the same time, these developments are advisory in nature, so the evaluation system of mutagenicity in different countries differs. First of all, it is the presence of phasing studies with different objectives of each stage and, accordingly, a different set of methods, allowing optimally to solve the main problem - to identify mutagens quickly and proficiently and to determine the degree of the risk for human somatic and germ cells. 


\section{Various methods for detection of mutagenic actions}

\section{Comprehensive overview of various methods}

The first phase (stage of detection of the mutagens) consists of experimental forecast, that is, analyzing the results of the previous studies of the mutagenicity, carcinogenicity, teratogenicity, and other dangerous biological characteristics of substances which are close to the study matter on the chemical structure, physico-chemical parameters, and others. For primary bolting (screening) of the potential mutagens, the experiments typically used the short-term tests for the account of gene mutations for microorganisms (Ames test Salmonella/microsomes) for the fruit flies of Drosophila or mammalian cell culture in vitro. In the case of a positive response, in the second phase, the material is subjected to research using mainly accounting methods of the mutations on somatic and germ cells of the mammals and humans. These methods include consideration of the chromosomal aberrations in mammalian and human bone marrow cells, micronucleus test, taking into account the dominant lethal mutations in the germ cells of mice or rats, translocation test, taking into account the induction of DNA damage and repair systems in the human cells or mammalian cells and other methods, as well as the accounting methods of gene mutations.

International Programme on Assessment of express methods showed that there is no single test system, which would display a fairly high level of reliability that can be used without the help of the other systems. It is necessary to use complex tests not only to avoid false negatives, but also false-positive results [2]. Due to the fact that most test systems determine only one type of the genetic alterations in specific strains of microbes, lines and cell types having specific functional characteristics or morphological status, positive results are revealed in the study of the most chemical compounds on such microbial strains or the cell lines that are unique, often with perverted metabolism or abnormal structures.

\section{The mutagenic effects of chromium on bacteria}

Multiplanned and interesting scientific data was obtained in the study of the mutagenic action of the chromium compounds on bacteria [3]. This work used a compound of $\mathrm{Cr}$ (VI)_chromates, sodium, potassium, potassium dichromate, sodium, ammonium, and $\mathrm{Cr}$ (III) - the chrome and potassium alum "dry chrome tanning agent", sulfate and chloride chromium at a concentration of 100-104 M. The salts of Cr (VI) to sublethal (103.5 M) and lethal (103 M) concentrations display the pronounced genetic effect: the processes of the genetic exchange in bacteria are inhibited during conjugation, display DNA-polymerase I activity (PoI-activity), increase the frequency of mutation. At the same time, $\mathrm{Cr}$ (VI) is not active in the plate-tests for reversion to protoprophy on amber- and okhre mutants of Escherichia A2 and WWI. The ions of Cr (VI) indicate in bacteria nonreparable and reparable DNA-polymerase prelethal damage. The ions of $\mathrm{Cr}$ (VI) and $\mathrm{Cr}$ (III) in all the studied concentrations (102-104 M) were inactive as elementary plasmin and converting phages in vivo and in vitro. The salts of $\mathrm{Cr}$ (III) at $\mathrm{pH} 7.0-9.0$ are slightly toxic to bacteria, do not display poI- and ivg-activity and display no effect on the processes of the genetic exchange in bacteria during conjugation.

The frequency of the dominant lethal mutations (DLM) on the concentration of the potassium dichromate and duration of exposure was shown in further studies [4]. As a test object was used classic genetic studies on Drosophila melanogaster, the line D-32, characterized by the lowest possible level of the spontaneous mutation. The experiments were set according to the scheme, which allows to record the frequency of the DLM in several generations. Potassium dichromate was added in the nutrient medium in the concentrations of $0.2,0.4,0.8,1.0,2.0,3.0 \%$ aqueous solution and considered frequency of early embryonic lethality (REL), late embryonic (PEL) and DLM common frequency for 20,30, $40 \mathrm{~h}$ or more; determined the survival rate of eggs in clutches for each concentration. In the analysis of the frequency of DLM induced by the potassium dichromate, the first generation shows a statistically significant increase in the frequency of the DLM for all studied concentrations of the potassium dichromate compared with the control level. The DLM frequency increases with increasing concentration of the chromium. In particular, increasing of the mutagenicity of the potassium dichromate correlates with the duration of exposure, after $144 \mathrm{~h}$ of exposure, revealed the maximum mutagenic effect. There was also found the increased frequency of the mutations in a number of subsequent generations.

\section{Mutagenic effects of chromium on Drosophila melanogaster}

Mutagenic studies of the chromium on $D$. melanogaster by the DLM results in the following: the potassium dichromate are in a linear function from the concentration and exposure, and the mutagenic effect of the chromium chloride is in a non-linear dependence [5]. The concentration dependence of the mutagenic effect of the chromium chloride largely varies with the type and composition of the nutrient medium. In particular, the mutagenic effect of the chromium is detected at lower concentrations than the 
potassium dichromate by using sugar as the nutrient medium. Increase of mutational effect was not observed on the further increasing of the chromium concentration.

\section{The effect of potassium dichromate}

It was shown that a significant proportion of the spontaneous mutational process conditioned by mobile elements can move within the genome of the cell $[6,7]$. The possibility of moving of the mobile genetic elements (transposons) under the action of the chromium in the bacterial strains and plasmids [Ecoli C600 (pSA 2001) - (Rp4ts 12) :: Ap2 (Ts 1); MC 4100 lac :: Ts 9] has been studied. The task was to study the effect of the potassium dichromate on the induction of transposition and excision of transposons Ts 1 and $\mathrm{T}$ 9. The following concentrations of the potassium dichromate-3.0, 7.5, $15.0 \mathrm{mg} / \mathrm{mL}$ [8] were used. The potassium dichromate at concentrations of 7.5, $15.0 \mathrm{mg} / \mathrm{ml}$ causes induction of the transposition process, which indicates a violation of the protective mechanism of the cell limiting the frequency of transposon movement.

Sex-linked recessive lethal mutations, along with chromosome and chromatid, occur in the processing of male germ cells in the premeiotic, meiotic and postmeiotic stages of spermatogenesis with the potassium dichromate ( $0.6 \%$ solution of the potassium dichromate; Drosophila line Muller-5 (M-5), low mutabilis line D-32) [9]. The frequency of the chromatid mutations in all series of experiments ranges from 0.48 to 1.75 and is significantly lower than the frequency of the chromosomal mutations (from 0.97 to 3.05 ). In view of the low mutability of Drosophila flies (line D-32), the recorded frequency of the chromosome and chromatid mutations in the test samples indicates that almost all of the mutations were induced by the potassium dichromate. Correction for spontaneous mutability practically does not incorporate the changes in the results of experiments.

\section{Genotoxic potential of chromium salts}

Study of the genotoxic potential of the salts of the chromium, molybdenum, tungsten on the vegetational test systems [Tradescantia clone, Crepis capillaries L, Soybean (Glycine max (L.) Merill)] revealed not only the mutagenic effect, but also the features of isolated and combined effects of these chemicals. Studies for testing of the heavy metals of the three vegetational sites established the presence of the pronounced genotoxic effect in the potassium dichromate; spectral analysis of the chromosomal aberrations showed that single and paired fragments range the bulk of damages. A similar pattern of the change has been installed despite the fact that each of the test systems displays different sensitiveness, actual- and tissue specificity.
The potassium dichromate has the highest genetic activity among these heavy metals. The salts of sodium molybdate and sodium tungstate exert the modifying action in subtoxic concentrations that resulted in the increasing of the mutagenic activity of the potassium dichromate [10]. Investigation of the combinational mutagenic effect of the chromium and manganese on the model microbial mutations also showed the presence of the modifying action of these metals with each other [11].

The chromic anhydride, as well as bichromates and monochromatic sodium and the potassium is capable of inducing chromosomic aberrations and changing of their numbers [12]. Experiments conducted on rats, which were administered chromic anhydride intra-abdominally in concentrations of $0.1,1.0,10.0 \mathrm{mg} / \mathrm{kg}$. The study of bone marrow cells showed that the value of the mitotic index, at the concentrations used by chromic anhydride, practically does not change. Maximum frequency of the aberrant cells induced by the chromium is observed at the concentration of $0.1 \mathrm{mg} / \mathrm{kg}$ and at the concentration of $1 \mathrm{mg} / \mathrm{kg}$, these figures getting lower. The main types of the chromosome aberrations are single fragments and single acentric rings. Chromic anhydride significantly affects the frequency of aneuploid cells.

\section{Comparison of various methods}

\section{Bichrome mutagenic and genotoxic effect in acute and long-term experiment}

These data confirm the activity of the cytogenetic chromic anhydride. Cr (VI) compounds display high mutagenic potential, while $\mathrm{Cr}$ (III) compounds are genetically inactive. At the same time, in the manufacturing environment is available changing of their valence, entailing increased mutagenic hazard Cr (III) [13]. The ability of chromium and its compounds for bioaccumulation, increasing growth of doses of the chromium lead to strengthening of their mutagenic activity [13]. A single intra-abdominal injection of male mice with low doses of the potassium dichromate did not induce dominant lethal mutations and the chromosomal aberrations in the bone marrow cells. However, prolonged (24 days) administration of the same dose results in a significant increase in the number of dominant lethal mutations. Likewise, injection on rats of the potassium dichromate (intratracheally at a dose of $1 \mathrm{mg} / \mathrm{kg}$ or with food, $0.2 \mathrm{ml}$ of $5 \%$ solution) caused no mutagenic effect of single exposure; exposure for a year resulted in an increase in the number of the aneuploidy cells, the chromosomal aberrations, variations in the degree of coiling of the chromosomes of the bone marrow $[14,15]$. 
Table 1 Results of the bone marrow cells' chromosomal analysis of the rats, affected by bichrome acute and long-term exposure

\begin{tabular}{|c|c|c|c|c|c|c|c|c|}
\hline \multirow[t]{3}{*}{$\begin{array}{l}\text { Group of } \\
\text { animals }\end{array}$} & \multirow[t]{3}{*}{ Exposure } & \multirow[t]{3}{*}{$\begin{array}{l}\text { Number of analyzed } \\
\text { metaphases }\end{array}$} & \multicolumn{2}{|c|}{$\begin{array}{l}\text { Number of metaphases } \\
\text { with aberrations (\%) }\end{array}$} & \multicolumn{4}{|c|}{ Chromosomal aberration over 100 cells } \\
\hline & & & \multirow[t]{2}{*}{$M \pm m$} & \multirow{2}{*}{$\begin{array}{l}\% \text { to } \\
\text { control }\end{array}$} & \multirow{2}{*}{$\begin{array}{l}\text { Total } \\
\text { number }\end{array}$} & \multicolumn{3}{|c|}{ Types of aberration (\%) } \\
\hline & & & & & & $\begin{array}{l}\text { Single } \\
\text { fragments }\end{array}$ & $\begin{array}{l}\text { Geminated } \\
\text { fragments }\end{array}$ & Exchanges \\
\hline 1 st $(n=8)$ & Control & 500 & $1.6 \pm 0.56$ & 100.0 & 1.6 & 87.5 & 12.5 & 0 \\
\hline 2 nd $(n=8)$ & Acute & 364 & $\begin{array}{l}14.6 \pm 2.00 \\
p_{1-2}<0.01\end{array}$ & 912.5 & 19.9 & 67.7 & 1.3 & 1.9 \\
\hline 3 rd $(n=7)$ & $\begin{array}{l}\text { Long-term } \\
\qquad(2 \text { months })\end{array}$ & 487 & $\begin{array}{l}7.0 \pm 1.20 \\
P_{1-3}<0.02\end{array}$ & 309.7 & 7.0 & 72.8 & 9.5 & 17.5 \\
\hline 4th $(n=7)$ & $\begin{array}{l}\text { Long-term } \\
\text { (3 months) }\end{array}$ & 400 & $\begin{array}{l}12.05 \pm 1.76 \\
P_{1-4}<0.01\end{array}$ & 533.1 & 12.8 & 72.1 & 15.8 & 12.0 \\
\hline
\end{tabular}

$p$ values are given only for statistically significant changes $(p<0.05)$ in comparative groups

The above scientific evidence shows that the Cr (III), along with the $\mathrm{Cr}(\mathrm{VI})$, is capable of exerting of mutagenicity in the mammalian cells. A new step in the evaluation of the genotoxicity of the Cr (III) was made in the subsequent studies in which the chemical leads to changes on the part of the somatic and germ cells, manifested in the form of intrachromosomal rearrangements (sister chromatid exchanges) and the chromosomal aberrations [16, 17]. Genotoxicity of the $\mathrm{Cr}$ (III) is also proved in the experiments on the test systems [18], and violations of the processes of the DNA replication [19] performed in vitro.

In our genuine research carried out on experimental animals (rats of WAG line), we have studied particular issues associated with bichrome mutagenic and genotoxic effect in acute and long-term experiment. In the acute experiment, bichrome was administered intragastrically onetime in a dose of $10 \mathrm{mg} / \mathrm{g}$; in the long-term experiment, bichrome was given in a dose of $1 \mathrm{mg} / \mathrm{kg}$ during 2 and 3 months omni die. Acute exposure by bichrome was accompanied by substantial increasing of chromosomal aberration frequency; with a considerable quantity of the last one accounted for the share of geminated fragments and exchange displacement (Table 1). Under long-term methysis, chromosomal aberration increase in bone marrow cells was also determined.

\section{Testis tissue histological examination of the animals affected by bichrome acute exposure}

We have also carried out testis tissue histological examination of the animals affected by bichrome acute exposure. Cytological profile of the convoluted tubules' spermatogenesis is represented in the Figs. 1, 2, 3, 4, 5, 6.

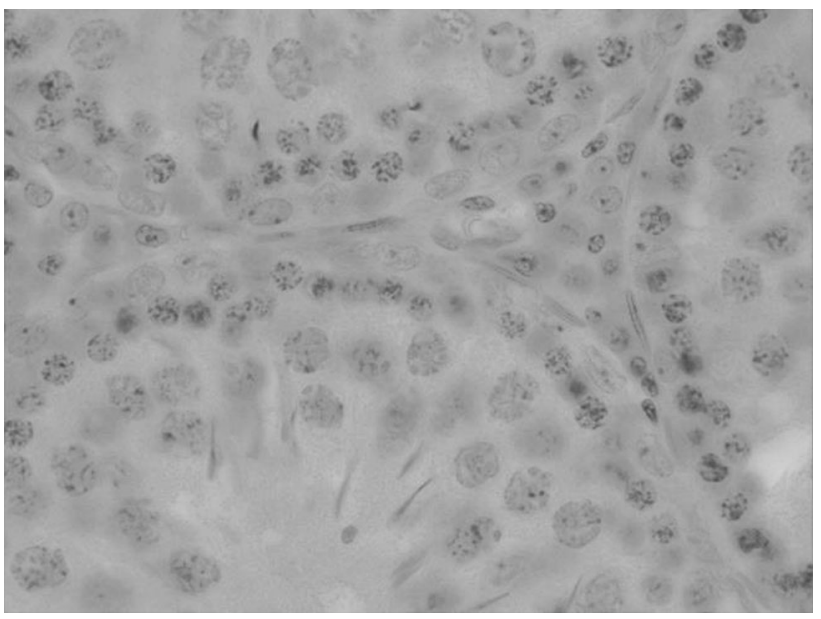

Fig. 1 Testis convoluted tubules cross-section in preleptotene stage. $\mathrm{H} \& \mathrm{E} \times 1000$

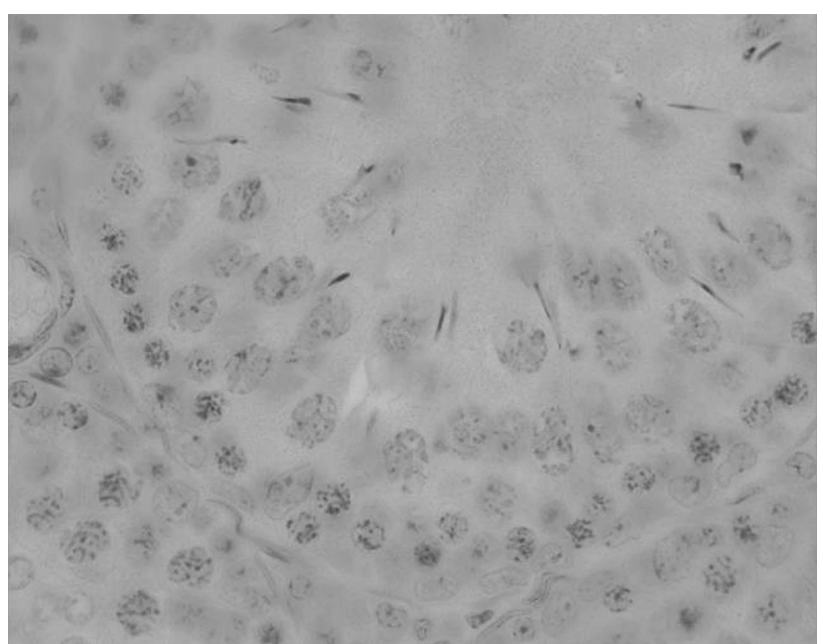

Fig. 2 Testis convoluted tubules cross-section in preleptotene and leptotene stage. $\mathrm{H} \& \mathrm{E} \times 1000$ 


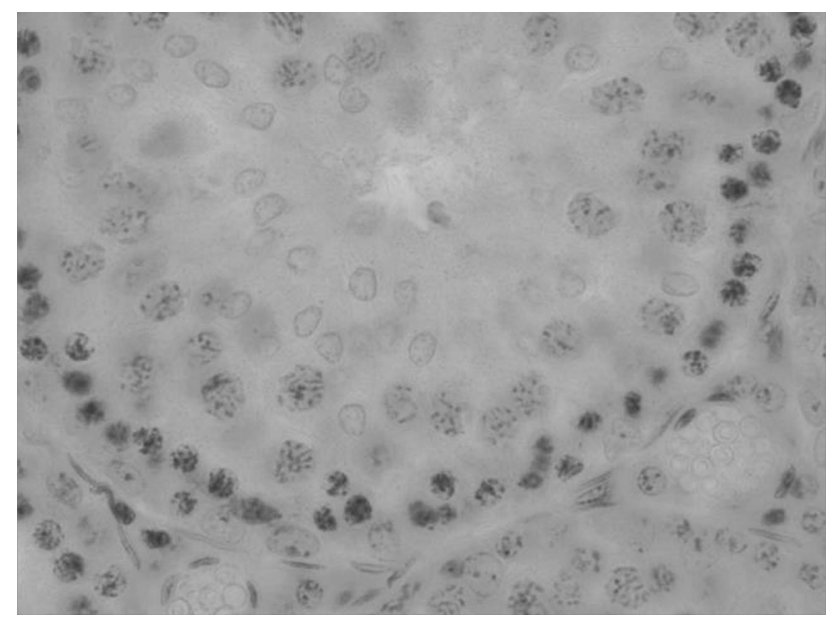

Fig. 3 Testis convoluted tubules cross-section in leptotene and zygotene stage. $\mathrm{H} \& \mathrm{E} \times 1000$

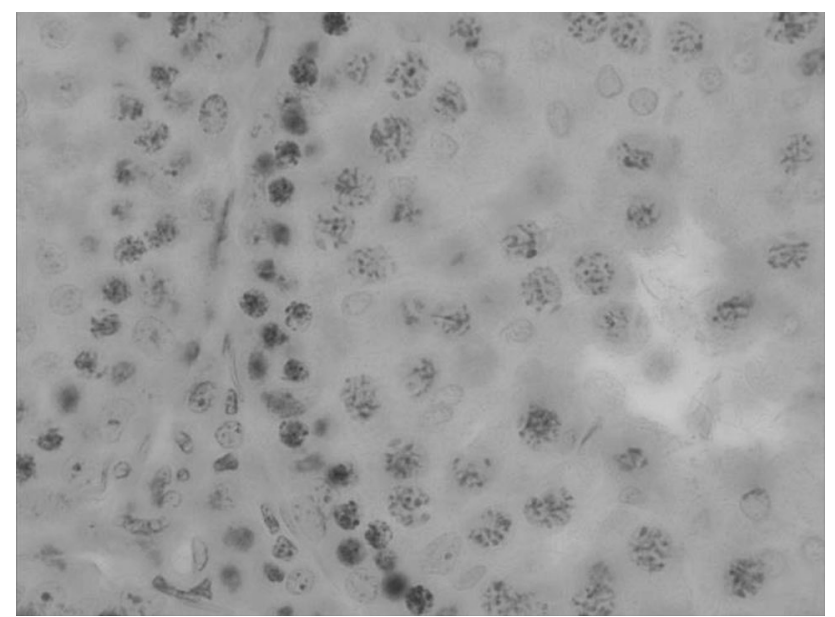

Fig. 4 Testis convoluted tubules cross-section in zygotene stage. $\mathrm{H} \& \mathrm{E} \times 1000$

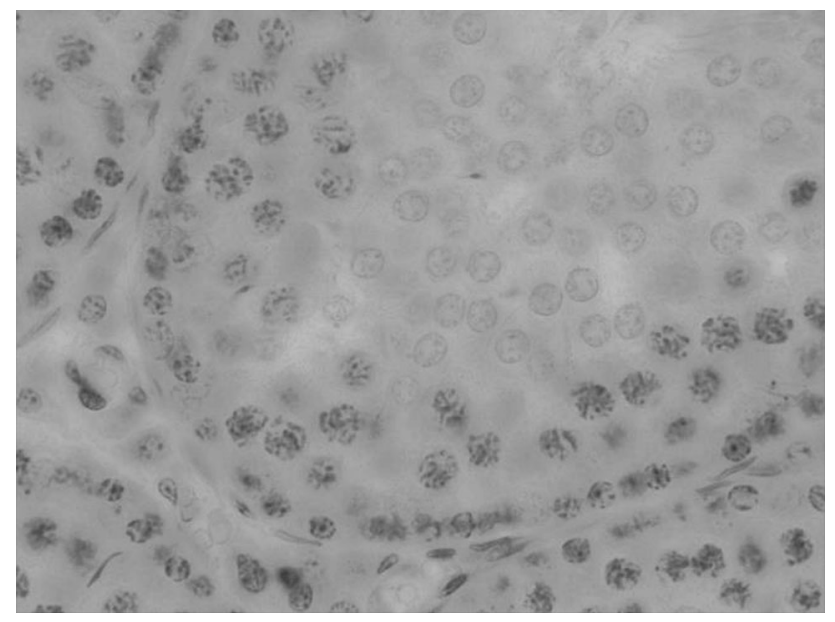

Fig. 5 Testis convoluted tubules cross-section in pachytene stage. $\mathrm{H} \& \mathrm{E} \times 1000$

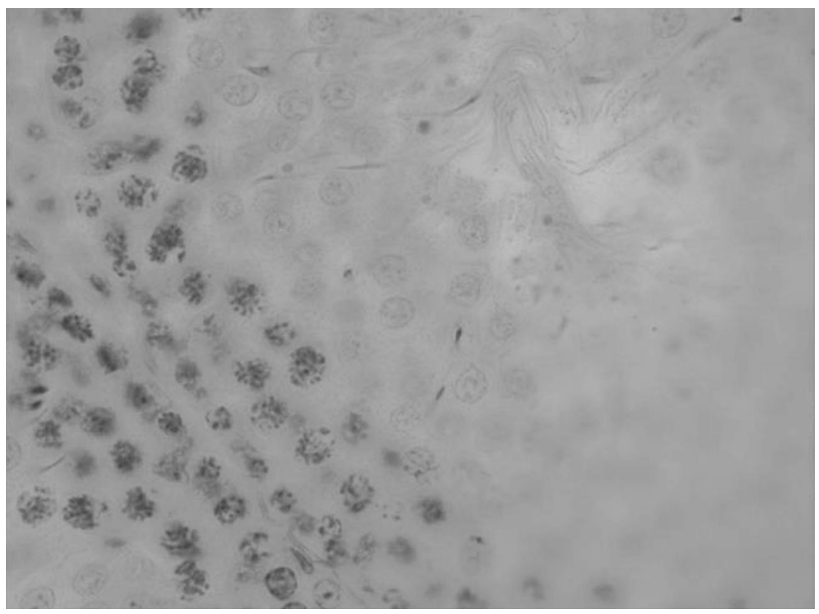

Fig. 6 Testis convoluted tubules cross-section in diplotene and diakinesis stage. $\mathrm{H} \& \mathrm{E} \times 1000$

We have been also identifying prophase stages of the reduction division in the rats of the experimental and control group (Table 2). Comparison of the convoluted tubules' average diameter of the control animals and the experimental group, showed diameter and lumen increase of the seminiferous tubules in the bichrome-exposed animals. Thus, convoluted tubules' average diameter of the control animals was $263.72 \pm 2.37 \mu \mathrm{m}$, convoluted tubules' diameter of the experimental animals increased $10 \%$ more, being $291.15 \pm 3.11 \mu \mathrm{m}$. At that, sharp decrease of the spermatogenesis coefficient took place, which decreased by $68 \%$; also considerable increase of the number of tubules with "plugs" took place.

In the next following experiments, carried out on males, bichrome was injected intraperitoneally during 2 months (dose of $25 \mu \mathrm{g} / \mathrm{kg}$ in recalculation to pure chrome), and in the experiment on females, bichrome was injected intraperitoneally during 15 days. Progression of chromic methysis was accompanied by the evident reproductive dysfunction both of males and of females (Table 3; Figs. 7, 8).

\section{Results of cytogenetic examination of workers}

An increased level of the chromosomal aberrations (aberrations of the chromatic and exchange types, the chromosome disrupts in the centromeric areas), was found in peripheral blood leukocytes in the study of workers exposed to the chromium [15]. Cytogenetic studies of workers, who were in contact with the chromium compounds of different valence, showed that the level of the chromosomal aberrations in peripheral blood leukocytes display no difference depending on the contact with different valence of the chromium and was significantly higher than the control $[15,20]$. Increasing the level of 
Table 2 Quantitative characteristics of the rats' testis generative kinesis after longlasting bichrome exposure

\begin{tabular}{lll}
\hline Parameters & Control & Experimental group \\
\hline Tubules diameter $(\mu \mathrm{m})$ & $263.72 \pm 2.37$ & $291.15 \pm 3.11$ \\
Spermatogenesis coefficient (number) & $4.1 \pm 0.39$ & $2.8 \pm 0.22$ \\
Number of tubules with "plugs" & $0.498 \pm 0.08$ & $0.776 \pm 0.09$ \\
Preleptotene spermatocytes of the 1st order $(\%)$ & 11.5 & 100 \\
Preleptotene and leptotene spermatocytes of the 1st order (\%) & 12.3 & - \\
Leptotene spermatocytes of the 1st order $(\%)$ & 20.1 & - \\
Leptotene and zygotene spermatocytes of the 1st order $(\%)$ & 18.3 & - \\
Zygotene spermatocytes of the 1st order $(\%)$ & 9.1 & - \\
Zygotene and pachytene spermatocytes of the 1st order $(\%)$ & 8.9 & - \\
Pachytene spermatocytes of the 1st order $(\%)$ & 9.5 & - \\
Pachytene and diplotene spermatocytes of the 1st order $(\%)$ & 5.2 & - \\
Diplotene spermatocytes of the 1st order $(\%)$ & 5.1 & - \\
\hline
\end{tabular}

* Differences statistically valid $(p \leq 0.05)$

Table 3 Bichrome influence on the reproductive function of the experimental animals

\begin{tabular}{|c|c|c|c|c|c|c|}
\hline Parameters & $\mathrm{CL}$ & IS & PreIL & LF & PostIL & TEL \\
\hline \multicolumn{7}{|l|}{ Males } \\
\hline Control & $10.2 \pm 0.32$ & $9.2 \pm 0.34$ & $9.8 \pm 0.32$ & $8.3 \pm 0.28$ & $9.4 \pm 0.5$ & $16.22 \pm 1.32$ \\
\hline $\mathrm{Cr}^{+6} .25(\mu \mathrm{g} / \mathrm{kg})$ & $12.5 \pm 0.29^{\circ}$ & $10.2 \pm 0.17^{\Delta}$ & $18.4 \pm 1.08^{\circ}$ & $6.9 \pm 0.26^{*}$ & $32.5 \pm 1.6^{\circ}$ & $45.0 \pm 1.58^{\circ}$ \\
\hline \multicolumn{7}{|l|}{ Females } \\
\hline Control & $12.0 \pm 0.44$ & $10.8 \pm 0.42$ & $9.9 \pm 0.8$ & $9.77 \pm 0.44$ & $9.2 \pm 0.4$ & $18.44 \pm 0.71$ \\
\hline $\mathrm{Cr}^{+6} .25(\mu \mathrm{g} / \mathrm{kg})$ & $12.1 \pm 0.3$ & $10.3 \pm 0.20$ & $15.0 \pm 1.58^{\Delta}$ & $7.4 \pm 0.24^{\circ}$ & $28.7 \pm 0.73^{\circ}$ & $40.0 \pm 1.31^{\circ}$ \\
\hline
\end{tabular}

$C L$ corpus luteum, $I S$ implantation site, PreIL pre-implantation loss, $L F$ live fetus, PostIL post-implantation loss, TEL total embryo loss

$* p \leq 0.05,{ }^{\Delta} p \leq 0.02,{ }^{\circ} p \leq 0001$ in comparison with control

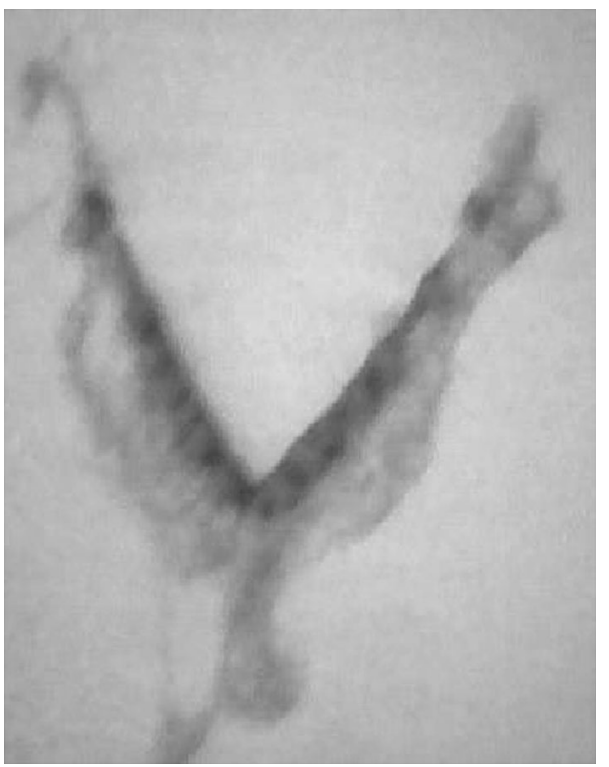

Fig. 7 Control group pregnant rat uterus. There are seven live embryos in each left and right uterine horn, there are no dead embryos

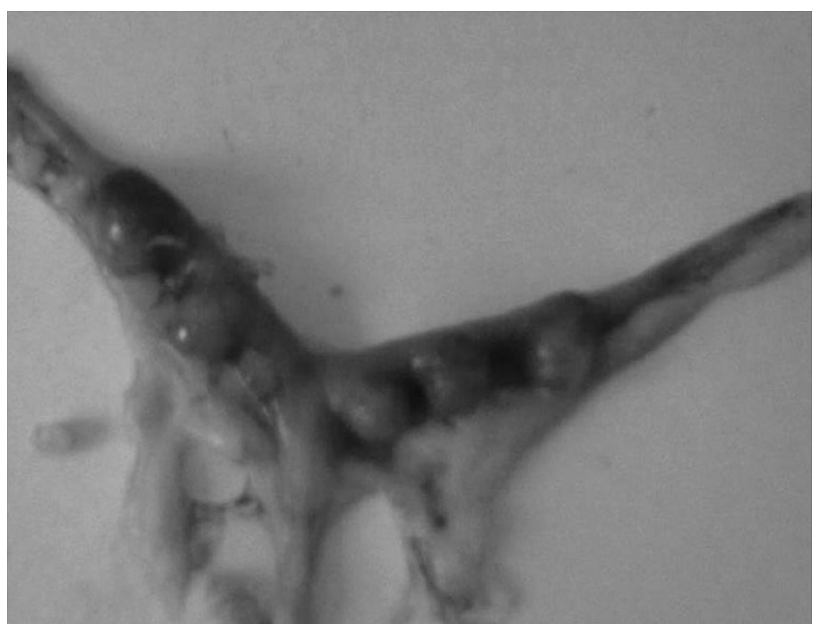

Fig. 8 Chrome-induced post-implantation embryos loss. There are two live and two dead embryos in the right uterine horn, there are three live and two dead embryos in the left horn

chromosomal abnormalities correlated with the duration of work in the enterprise. Survey of the trained workers exposed to the chromium, revealed the presence of 
fluctuations in the number of cells with the chromosome aberrations from 6.5 to $9.2 \%$, chromosome (40\%) and chromatid $(60 \%)$ aberration. Direct cytogenetic examination of workers showed that all studied compounds of the chromium [including the $\mathrm{Cr}$ (VI), the $\mathrm{Cr}$ (III)] induce the chromosome aberrations, which level increases progressively with increasing duration of exposure. The authors express the view that the incidence of the chromosomal aberrations is determined by the degree of accumulation of the chromium in organs and tissues.

Evaluation of the SCE in the lymphocytes of workers of the chrome production showed that the number of the SCE in cells varied in professional groups working from 2 to 32 , in the control group-from 2 to 25. Parameters of average number of the SCE per cell differed between individuals in both groups and ranged from 9.01 to 18.55 and from 8.07 to 9.38. The overall frequency of the SCE in the group of workers was significantly higher than in the control group: $11.17 \pm 0.54$ SCE per cell vs. $8.65 \pm 0.49$ [21]. Cytogenetic analysis revealed that the main types of the chromosome damage in the experimental group were single and paired acentric fragments and were rare chromatid and chromosome exchanges [22]. The average number of the sister chromatid exchanges per cell in the group of workers of the chrome factory was 11.3 , while in the control group, 8.7. Comparing the frequency of the chromosomal aberrations and the SCE of each individual found four different combinations of values of these parameters: a high frequency of the chromosomal aberrations, both high and low levels of the SCE, and vice versa.

\section{Discussion and overview}

Many aspects of the genotoxicity of the chromium and its compounds also have been studied by a number of authors. On a variety of the test systems has been shown not only the mutagenicity of the chromium and its compounds, but also the sensitivity and specificity of the methods [23-30]. A wide range of both structural and quantitative changes of the mutation process has been established in somatic and germ cells of the mammals and humans [31-36]. Accounting of the mutagenic effect of the chromium and its compounds in microorganisms and mammalian cell culture in vitro, as well as consideration of the chromosomal aberrations in the bone marrow cells of mammals and human cells, translocation test, account induction of the DNA damage and repair systems in the human and mammalian cells allows to establish the fact of genotoxicity of the chromium and its compounds with large argument.

The cytogenetic studies on the human cell culture (peripheral blood lymphocytes and embryonic fibroblasts) allow taking into account the nature and frequency of the normal number of the chromosome changes under the influence of the chemical agents and are valuable in the clinical examination of the chemical production workers. Research technique of the SCE displays a high sensitivity, which is also recommended for clinical and epidemiological testing of mutant prevention concentration (MPC) [37]. At the same time there is an opinion against using the accounting method for monitoring of the SCE by professionally exposed groups due to its high selectivity with reference to the mutagens. Evaluation of the micronucleus, which are the result of the structural and numerical chromosome aberrations, is recommended for use in the epidemiological studies as an indicator of the chemical mutagenesis. Disruptions and repair of the DNA damage are usually transient phenomenon that occurs at the moment of impact of mutagens and usually disappear quickly, making it suitable for probation population monitoring mutations, but also useful for assessing the genetic status of the organism and its sensitivity to the chemical environmental factors.

Methods for studying mitosis in different organs of experimental animals differ by sensitivity, simplicity and efficiency. The main consequence of the pathology of mitosis is the emergence of mutations and aneuploidy. Pathology of mitosis may be associated with the chromosomal damage, damage of the mitotic apparatus, a violation of cytokinesis [38]. The pathology of mitosis develops due to violation of biochemical processes in the cell, and therefore represents the cytotoxic effect of the studied chemical agents. It is possible that the mutagenic effect of the chromium and its compounds, determined by their general toxic and specific actions, leads to significant distortions of biochemical, biophysical, immunological processes in the body. Analysis of the mitosis will allow to identify all types of the genetic damage to estimate the mutagenic (cytogenetic) danger of the test compound. Contemporary methodological framework allows to detect not only the genomic and chromosomal mutations, but also the gene mutations. These methods are extremely complex and unsuitable for routine monitoring.

Etiological link of somatic genetic damage with the beginning of development of tumors can be recommended to use mutagenic tests as an indicator of possible blastomogenic activity of chemical compounds. Analysis of data of the parallel study of these effects indicates that the cytogenetic effect in the somatic tissue (bone marrow) appears much earlier and at lower levels of exposure, when blastomogenic effect (on adequate statistical groups) could not be detected [39]. The SCE and micronucleus test were isolated among other cytogenetic methods that have the greatest prognostic value in relation to the blastomogenic effect [40, 41]. The blastomogenic effect of chemical compounds is characterized by their capacity to induce 
development of benign or malignant tumors in humans. Availability expressed by the mutagenic properties of the chromium and its compounds, a wide range of the general toxicity and specific actions allow to extrapolate these data to the carcinogenesis and blastomatosis.

The above literary data indicate that the chromium and its compounds have pronounced mutagenic effect, on increased admission to organism of mammals and protozoa.

Conflicts of interest The authors declare that they have no conflict of interest.

\section{References}

1. WHO. Assessment of carcinogenicity and mutagenicity of chemical compounds. WHO Scientific Group. WHO Technical Report Series 1975; 546:24.

2. Adler J. Germ cell sensitivity in mammals. In: mutagens in our environment: proceedings of the 12th annual meeting of the European Environmental Mutagen Society, Espoo, Finland, June 20-24, 1982. p. 137-148.

3. Bondarenko VM, Karunnikova MM. The lethal and mutagenic action of chromium compounds on bacteria. In: Clinic, diagnosis and treatment of chromium toxicity and sensitization. Aktubinsk; 1981. p. 131-137.

4. Bigaliyev AB, Bakiyev IS. Mutagenicity studies of chromium on D. Melanogaster by DLM, message 1. Dependence of DLM frequency on the concentration of potassium dichromate and duration of exposure. In: Clinic, diagnosis and treatment of chromium intoxication and sensitization. Aktubinsk; 1981. p. $115-117$.

5. Bakiyev IS, Turetaeva AD. Mutagenicity studies on D. Melanogaster chromium by DLM, message 2 . Comparative analysis of DLM frequency under the action of 3- and 6-valent chromium compounds. In: Clinic, diagnosis and treatment of chromium intoxication and sensitization. Aktubinsk; 1981. p. 122-125.

6. Khesin YaS. Dimensions of the nuclei and cell functions. Science, 1967. p. 487.

7. Bochkov NP. Mutagenesis of humans. Bull Med Sci USSR. 1976;7:47-53.

8. Minseitova SR, Dzhusupkalieva MM. Efficiency of displacement of transposon Tn 1 and Tn 9 under the action of chromium compounds and boron. In: Clinical and hygienic aspects of the effect of chromium and other chemicals on the organism. Part 1. Aktubinsk; 1990. p. 99-101.

9. Bakiyev IS, Minseitova SR, Dzhusupkalieva MM. Study of longterm effects of the mutagenic effect of potassium dichromate in the experiment. In: Clinical and hygienic aspects of the effect of chromium and other chemicals on the organism. Part 1. Aktubinsk; 1990. p. 96-98.

10. Gogua ML. Study of the genotoxic potential of chromium, molybdenum, tungsten salts, on floral test systems. Author's abstract, 2003. p. 24.

11. Belezin SL, Saychenko SP. Features of combined mutagenic effect of chromium and manganese on the model of microbial mutations. Hyg Sanit. 1988;12:22-4.

12. Elemesova MSH. The study of the cytological and cytogenetic activity of chromic anhydride on rats. In: Clinic, diagnosis and treatment of chromium intoxication and sensitization. Aktubinsk; 1981. p. 117-120.

13. Patin Y, Kozachenko VI. The mutagenic activity of chromium compounds. Hyg Sanit. 1981;5:46-9.
14. Bigaliyev AB. Cytogenetic study in vivo of mutagenic features of chromium compounds. In: Genetic consequences of environmental pollution. Nauka; 1977. p. 173-176.

15. Bigaliyev AB. Genetic effects of heavy metal ions. Alma-Ata, 1986. p. 178.

16. Elias Z, Schneider O, Aubry F, Daniere MC, Poirot O. Sister chromatid exchanges in Chinese hamster V79 cells treated with the trivalent chromium compounds, chromic chloride and chromic oxide. Carcinogenesis. 1983;4:604-11.

17. Sarto F, Cominato I, Bianchi V, Levis AG. Increased incidence of chromosomal aberration and sister chromatid exchanges in workers exposed to chromic acid $\left(\mathrm{CrO}_{3}\right)$ in electroplating factories. Carcinogenesis. 1982;3:1011-6.

18. Bronzetti G, Galli A, Boccardo P, Del Carratore R, Edel J, Sabbioni E. Genetic effects of trivalent chromium on Saccharomyces cerevisiae. Sci Total Environ. 1988;71:3-570.

19. Snow ET, Xu L-S. Effects of chromium (III) on DNA replication in vitro. Biol Trase Elem Rep. 1989;21:61-71.

20. Bigaliyev AB, Turebaev MN, Bigalieva RK, Elemesova MSH. Cytogenetic examination of persons engaged in the production of chrome. Genetics. 1977;13(3):545-7.

21. Azhayev SA. Sister chromatid exchanges in lymphocytes of workers of chrome production. In: Clinical features, diagnosis and treatment of chromium toxicity and sensitization. Aktubinsk; 1981. p. 70-71.

22. Azhayev SA. Comparative evaluation of chromosomal aberrations and sister chromatid exchanges in lymphocytes of persons exposed to chromium. In: Clinic, diagnosis and treatment of chromium intoxication and sensitization. Aktubinsk; 1981. p. $120-121$.

23. Bianchi V, Celotti L. Sensibilizzazione di cellule di hamster in colturamediantetrattementiripetuti con bicromatopotassio. Bull Zool. 1975;42(4):435-6.

24. Bianchi V, Levis AG. Review of genetic effects and mechanisms of action of chromium compounds. Sci Total Environ. 1988;71(3):351-5.

25. Bronca M, Dessi A, Koziovski H, Micera G, Serra MV. In vitro interaction of mutagenic chromium (VI) with red blood cells. FEBS Lett. 1989;257(1):14-6.

26. Elias Z, Poirot O, Schneider O, Daniere MC, Terzetti F, Yuedenet JC, Cavelier C. Cellular uptake, cytotoxic and mutagenic effects of insoluble chromic oxide in V79 Chinese hamster cells. Mutat Res. 1986;169:159-70.

27. Fradkin A, Janoff A, Loune BP, Kuschner M. In vitro transformation of BHK 21 cells grown in the presence of calcium chromate. Cancer Res. 1975;35:1058-63.

28. Palierao SR, Landolph SR. Soluble insoluble hexavalent chromate. Relationship of mutation to in vitro transformation and particle uptake. Biol Traseelem Res. 1989;21:469-74.

29. Tsuda H, Kato K. Chromosome aberrations and morphological transformation in hamster embryonic cells treated with potassium dichromate in vitro. Mutat Res. 1977;46(2):87-94.

30. Venit S, Levy LS. Mutagenicity of chromates in bacteria and its relevance to chromate carcinogenesis. Nature. 1974;250: 493-5.

31. Farell RP, Jbdd RS, Lay PA, Dixon NE, Baker RS, Bonin AM. Chromium (V) induced cleavage of DNA: are chromium (V) complexes in chromium (V)—induced cancers. Chem Res Toxicol. 1989;2(4):227-9.

32. Fornase AJ, Seres DS, Lechner JF, Harris CC. DNA-protein crosslinking by chromium salts. Chem-Biol Interact. 1981;36: 345-54.

33. Gao M, Snow E, Sing J, Zhikovich A, Costa M. Unlike chromium (III) alone, low concentrations of amino acid-chromium (III)DNA-crosslinks act as strong blocks to DNA replications: Abstr Environ Mutagen Soc: 26th Annu Mut. 1995. 
34. Gomez Arroyo S, Aitmarino M, Villalobes-Pietrini R. Sister chromatids exchanges induced by some chromium compounds in human lymphocytes in vitro. Mutat Res. 1981;90:425.

35. Hamilton JW, Weterhahn KE. Differential effects of chromium (VI) on constitutive and inducible gene expression with chromium (VI) induced DNA damage. Carcinogenesis. 1989;2(5):274-86.

36. Rainaldi G, Colella CM, Pirs A, Mariana I. Thioguanine resistance, ovabain resistance and sister chromatid exchanges in $\mathrm{V}$ 79/AP4 XHO treated with potassium dichromate. Chem Biol Interact. 1982;42:45.

37. Bochkov NP, Demin YUS, Luchnic NV. Classification and accounting methods of chromosomal aberrations in somatic cells. Genetics. 1972;8(5):133-41.
38. Bochkov NP. Medical and biological approaches to cytogenetic monitoring of human population. In: Liss AR editor. Mutagens in our environment. Espoo; 1982. p. 101-109.

39. Alov IA. Problem of pathology of mitosis. Results of science and technology. Cytology. VINITI. 1976;3:40-65.

40. Sanotsky IV, Fomenko VN. The long-term consequences of the effects of chemicals on the organism. Medicine. Moscow, 1979. p. 230.

41. Chaubey RC, Kavi BR, Chauhen PS, Sundaram K. The evaluation of micronucleus test as an "in vitro" cytogenetic technique in mouse. Mutat Res. 1978;53(2):164-76. 